\title{
Potentially Modifiable Risk Factors in the Development of Alzheimer's Disease
}

\author{
Simon Forstmeier ${ }^{1}$ and Andreas Maercker ${ }^{2}$
}

1. Senior Researcher; 2. Professor, Psychopathology and Clinical Intervention, University of Zurich

\section{Abstract}

This article summarises empirical findings on major potentially modifiable risk factors in the development of Alzheimer's disease (AD), drawing on data from longitudinal epidemiological studies on the incidence of AD or any-cause dementia. Risk factors investigated to date include cognitive ability, motivational ability, emotional health, physical activity, social activity and social network, vascular risk factors and nutrition. The authors find most empirical support for two main clusters of risk factors that also represent potential targets for prevention. First, an active and stimulating lifestyle including cognitive, social, and physical activities reduces the risk of AD. Second, the absence of vascular risk factors such as diabetes, hypertension, hypercholesterol and obesity reduces the risk of AD. More prevention trials are warranted to investigate the preventative effects of an active and stimulating lifestyle on the one hand, and vascular health on the other, in delaying the onset of $A D$ or slowing its progression.
\end{abstract}

\section{Keywords}

Alzheimer's disease, risk factors, motivational reserve, cognitive reserve, social network, vascular risk factors, nutrition, prevention

Disclosure: The authors have no conflicts of interest to declare.

Received: 16 January 2009 Accepted: 26 August 2009 DOI: 10.17925/USN.2010.05.02.18

Correspondence: Simon Forstmeier, Department of Psychology, Division of Psychopathology and Clinical Intervention, University of Zurich, Binzmuehlestr. 14/17, 8050 Zurich,

Switzerland. E: s.forstmeier@psychologie.uzh.ch

As the number of people over 65 years of age continues to rise worldwide, preserving the cognitive health of older adults has become a major societal challenge. The global prevalence of Alzheimer's disease (AD) was estimated at 26.55 million in 2006 and is expected to quadruple over the next 40 years. ${ }^{1}$ However, research on successful ageing challenges the popular notion that ageing invariably involves a decline in cognitive functioning and quality of life, and has identified factors that can increase individuals' 'health span' as they enter later life. ${ }^{2}$ If onset or progression of AD could be delayed by only one year, there would be 9.2 million fewer cases of the disease in 2050. ${ }^{1}$ The goal of current research on $A D$ and other dementias is thus to identify both biological and psychological factors that may help people to maintain or enhance their cognitive health in older age and to prevent or postpone the development of dementia.

The most well-established risk factors for $A D$ and other dementias are old age, genetic susceptibility, familial aggregation and female sex. However, modifiable risk factors are more important for the development of prevention strategies. In this article, we summarise empirical findings on the major modifiable risk factors of AD. We base our overview and conclusions on several recent review papers as well as on a systematic review of our own, which aimed to include all published studies providing an estimate of the incidence of $A D$ or dementia ('relative risk') associated with the risk factor examined (see Table 1). We included only longitudinal studies whose results were adjusted at least for age, sex, and education. Due to space restrictions, we cite only example studies and summarise the findings of our review in Table 1. The interested reader is referred to the review papers presented in Table 1 and to more general overview articles. ${ }^{3-6}$ Note that in epidemiological studies, AD is usually diagnosed on the basis of clinical features rather than neuropathological evidence.

\section{Cognitive Ability}

Dozens of longitudinal studies suggest that lower pre-morbid cognitive ability increases the risk of $A D$ and dementia. Four different measures have been used to estimate pre-morbid cognitive ability: educational level, pre-morbid performance in cognitive tests, amount of cognitive activity and occupational attainment.

\section{Educational Level}

Educational level is usually assessed as a two- or three-category variable (e.g. $<8$ years, $\geq 8$ years). We identified 15 studies, 11 of which found a significantly increased risk of $A D$ or any-cause dementia in less educated individuals. ${ }^{7.8}$ A recent meta-analysis calculated a relative risk of low versus high educational level of 1.8 (95\% confidence interval $[\mathrm{Cl}]$ 1.4-2.3) for $\mathrm{AD}$ and 1.6 (95\% Cl: 1.3-2.0) for all dementias. ${ }^{9}$ Although there is strong evidence that education to a low standard is a risk factor for $A D$, the mechanisms underlying this association are not yet clear. Most authors explain the protective effect of education in terms of cognitive reserve: ${ }^{10}$ education is thought to stimulate underlying brain networks and make them more efficient and flexible. In individuals with higher cognitive reserve, the underlying brain pathology may not become clinically manifest until later because their brain networks are more capable or because different, intact networks are used to replace or bypass the disrupted networks. Other explanations of the association between education 
and dementia suggest that education is strongly linked with early life circumstances (e.g. socioeconomic status), motivational ability or health behaviour (e.g. nutrition and physical activity).

\section{Pre-morbid Intelligence}

Two studies using a more direct measure of pre-morbid intelligence found a significant association between performance in cognitive tests and risk of $A D$ or dementia. In one study, a measure of verbal intelligence (which is considered to provide a good estimate of premorbid intelligence) applied at baseline was a better predictor of incident dementia four years later than was educational level." Another study in which several memory and intelligence tests were applied at baseline found that lower memory function predicted higher risk of dementia 22 years later. ${ }^{12}$

\section{Cognitive Activity}

Seven studies were identified that investigated the relation between participation in cognitive activities (e.g. reading books and newspapers, writing, studying, doing crossword puzzles) in mid- to late life and risk of $A D$ and dementia. Almost all (six) studies found a reduced risk of $A D$ in individuals who frequently engaged in cognitive activities (e.g. relative risk $0.4,95 \% \mathrm{Cl} 0.2-0.7$ ), even when the APOE 4 allele was controlled..$^{13}$

\section{Occupational Attainment}

Occupational activities may provide a source of continued cognitive stimulation, contributing to the development of cognitive reserve. Five of the six longitudinal studies identified used a two-category variable of occupational attainment, e.g. low level (unskilled, semiskilled) versus high level (self-employed, professional, skilled). Only two of these five studies found that people who worked in low-skilled occupations had a higher risk of AD or dementia (e.g. relative risk 2.3, 95\% Cl 1.3-3.8). ${ }^{14} \mathrm{~A}$ different approach is to rate each occupation in terms of the complexity of work with data, people and things. One longitudinal study found a decreased risk of all-cause dementia, but not $A D$, in people who have worked in occupations characterised by high complexity of work with people and things. ${ }^{15}$

In sum, lower cognitive ability seems to be a risk factor for $A D$ and dementia in general. Results differ depending on the measurement approach. Although educational level, pre-morbid intelligence and cognitive activities are clearly linked to $A D$ and any-cause dementia, findings for occupational attainment are less conclusive, presumably because this variable depends not only on cognitive ability, but also on motivational, social and other abilities. ${ }^{16}$

\section{Motivational Ability}

The concept of brain reserve is more comprehensive than that of cognitive reserve. Brain reserve enables the brain to tolerate neuropathological dementia-related changes without clinical manifestation. In the case of behavioural brain reserve, ${ }^{17}$ behavioural and mental training throughout life is assumed to promote the more efficient use of brain networks and compensation of disrupted networks. We have suggested that not only pre-morbid cognitive ability but also pre-morbid motivational ability contributes to brain reserve. ${ }^{16}$ We hypothesise that people with strong motivational abilities (e.g. decision regulation, activation regulation, motivation regulation and self-efficacy) have a lower risk of AD. Epidemiological research has shown that motivational ability is associated with some mental and physical disorders and risk factors for AD (e.g. depressive symptoms, educational and occupational attainment, physical activity), suggesting
Table 1: Summary of Studies Investigating Potential Risk Factors for Alzheimer's Disease

\begin{tabular}{lllll} 
Potential Risk Factor & $\begin{array}{l}\text { Significant } \\
\text { Association } \\
\text { Found }\end{array}$ & $\begin{array}{l}\text { No } \\
\text { Significant } \\
\text { Association } \\
\text { Found }\end{array}$ & $\begin{array}{l}\text { Review or } \\
\text { Meta- } \\
\text { analysis }\end{array}$ & $\begin{array}{l}\text { Example } \\
\text { Studies }\end{array}$ \\
\hline Cognitive Ability & 11 & 4 & 9,45 & 7,8 \\
\hline Educational level & 2 & 0 & & 11,12 \\
\hline Pre-morbid IQ & 6 & 1 & 46 & 13 \\
\hline Cognitive activity & 2 & 4 & 45 & 14 \\
\hline Occupational & & & &
\end{tabular}

attainment

\begin{tabular}{|c|c|c|c|c|}
\hline \multicolumn{5}{|l|}{ Motivational Ability } \\
\hline Conscientiousness & 1 & 0 & & 19 \\
\hline \multicolumn{5}{|l|}{ Emotional Health } \\
\hline Depression & 5 & 6 & 20 & 21 \\
\hline Neuroticism & 3 & 0 & & 22 \\
\hline Physical Activity & 12 & 4 & 46 & 23,24 \\
\hline \multicolumn{5}{|l|}{ Social Activity } \\
\hline Social activity & 4 & 0 & 46 & 25 \\
\hline Social network & 4 & 0 & 46 & 26 \\
\hline \multicolumn{5}{|c|}{ Vascular Risk Factors } \\
\hline Diabetes & 6 & 5 & 27 & 28 \\
\hline Hypertension & 5 & 6 & 27 & 29 \\
\hline Hypercholesterol & 2 & 2 & 27 & 30 \\
\hline Obesity & 1 & 4 & 27 & 31 \\
\hline \multicolumn{5}{|l|}{ Nutrition } \\
\hline Homocysteine & 3 & 1 & 6,40 & 33 \\
\hline Vitamin $\mathrm{B}_{6}$ & 1 & 2 & 6,40 & 34 \\
\hline Vitamin $\mathrm{B}_{12}$ & 0 & 4 & 6,40 & 34 \\
\hline Folate & 5 & 1 & 6,40 & 34 \\
\hline Vitamin E & 3 & 4 & 6,40 & 35 \\
\hline Vitamin C & 1 & 5 & 6,40 & 35 \\
\hline Flavonoids & 0 & 3 & 6,40 & 35 \\
\hline Beta-carotene & 0 & 5 & 6,40 & 35 \\
\hline Polyunsaturated fat & 3 & 1 & 6,40 & 36 \\
\hline Diverse diet & 2 & 0 & 6,40 & 37,38 \\
\hline Fish & 2 & 1 & 6,40 & 39 \\
\hline
\end{tabular}

a more specific link to the development of $A D .^{16}$ We are currently conducting longitudinal studies to investigate this relationship, partly in co-operation with the German Competence Network on Dementia. ${ }^{18}$

Conscientiousness - one component of the five-factor model of personality - is a related construct that can be defined as the tendency to control impulses and to be goal-directed. Whereas motivational ability is assumed to be modifiable through training, conscientiousness is thought to be a stable personality trait. One longitudinal study found that relative risk of $A D$ is slightly lower in highly conscientious individuals, even after adjusting for numerous control variables (relative risk $0.97,95 \% \mathrm{Cl} 0.93-0.997) .{ }^{19}$

\section{Emotional Health}

A recent meta-analysis on the association of depression and risk of AD identified 11 longitudinal studies. ${ }^{20}$ Only half (five) of these studies found that the risk of AD was significantly higher in individuals who reported depressive symptoms earlier in life. ${ }^{21}$ The mean risk in this meta-analysis was $1.9(95 \% \mathrm{Cl} 1.6-2.3)$, suggesting that there is a link between depression and risk of AD. Depression often accompanies early dementia and may therefore be an early prodrome of dementia rather than an independent risk factor for AD. However, findings show that the interval between diagnoses of depression and $A D$ is positively 
related to risk of $A D$, indicating that depression seems to be a risk factor for rather than a prodrome of $A D .^{20}$

One possible explanation for the association between depression and risk of $A D$ is that depression may lead to increased cortisol levels in the hippocampus, and that prolonged exposure to cortisol contributes to hippocampal atrophy and, in the long run, to AD. If this is the case, people who are susceptible to psychological stress such as depression (i.e. people with the personality trait of neuroticism) should have a higher risk of AD. Three longitudinal studies investigated this association and found that pre-morbid proneness to psychological stress slightly increases the risk of $\mathrm{AD}$ (relative risk 1.05, 95\% $\mathrm{Cl} 1.01-1.09$ ). ${ }^{22}$

\section{Physical Activity}

Sixteen studies were identified that investigated the relationship between participation in regular (daily) physical activities (e.g. walking, dancing, swimming) in mid- to late life and risk of $A D$ and dementia. Most (12) studies found a reduced risk of $A D$ in individuals who frequently participated in physical activities (e.g. relative risk 0.6, 95\% $\mathrm{Cl} 0.3-0.9){ }^{23}$ The majority of these studies investigated the effect of physical activity in old age. However, a protective effect of physical activity in middle age has also been reported. ${ }^{24}$ Several possible mechanisms may underlie this association, including reduction of vascular risk factors, promotion of brain plasticity and brain reserve and general cognitive ability resulting in better health behaviour.

\section{Social Activity and Social Network}

Several longitudinal studies have investigated the protective effects of social factors such as social activity and social network on risk of $A D$ and dementia.

\section{Social Activity}

Four studies were identified that investigated the relationship between participation in regular social activities (e.g. going to the theatre, participating in social groups, visiting friends) in late life and risk of dementia. All studies found a reduced risk of dementia in individuals who frequently participated in social activities (e.g., relative risk 0.6, $95 \% \mathrm{Cl} \mathrm{0.4-0.9)}{ }^{25}$ Several possible mechanisms may underlie this association, including promotion of brain plasticity and brain reserve, and emotional health resulting from fulfilling relationships.

\section{Social Network}

The latter hypothesis can also be tested by investigating the social network as a risk factor (e.g. being single or divorced versus married) Four studies were identified that investigated the relationship between social network and risk of dementia. All studies found an increased risk of dementia in individuals with poorer social networks (e.g. relative risk $2.3,95 \% \mathrm{Cl} 1.3-4.7$ ). ${ }^{26}$ Rich social networks provide emotional support and cognitive simulation.

\section{Vascular Risk Factors}

The components of metabolic syndrome - diabetes, hypertension, hypercholesterol and obesity - are well-known risk factors for cardiovascular disease. There is also accumulating evidence that they are risk factors for $A D$ and dementia in general. Treatment of these conditions is thus an important target for prevention of dementia.

\section{Diabetes}

A recent systematic review identified 13 studies investigating the relationship between diabetes in mid- to late life and risk of $A D$ or of any-cause dementia. ${ }^{27}$ Six of the 11 studies focusing on AD found an increased risk for people with diabetes (e.g. relative risk 1.8, 95\% Cl $1.1-2.9){ }^{28}$ Five of the nine studies covering any-cause dementia reported an increased risk for people with diabetes (e.g. relative risk $1.5,95 \% \mathrm{Cl} 1.0-2.2){ }^{28}$ There was no clear difference in findings for diabetes in mid- versus late life.

\section{Hypertension}

Five of 11 studies found an increased risk of $A D$ in people with hypertension (e.g. relative risk $4.5,95 \% \mathrm{Cl} 1.5-13.1){ }^{29}$ Five of six studies found an increased risk of any dementia (e.g. relative risk 4.0, 95\% Cl 1.6-10.3). ${ }^{29}$ However, some studies showed that either elevated systolic or elevated diastolic blood pressure was associated with an increased risk of AD. There was a marked difference in findings for hypertension in mid- versus late life. All studies assessing blood pressure at mid-life found a significant association between hypertension and AD/dementia, compared with only one study assessing blood pressure in late life.

\section{Hypercholesterol}

Two of four studies found an increased risk of $A D$ in people with elevated total cholesterol (e.g. relative risk $2.8,95 \% \mathrm{Cl} 1.2-6.7$ ). ${ }^{30}$ Two of six studies found an increased risk of any dementia (e.g. relative risk 2.6, $95 \% \mathrm{Cl}$ 1.2-6.0). ${ }^{30}$ The studies reporting a significant association between high cholesterol and risk of $\mathrm{AD} /$ dementia assessed cholesterol levels in mid-life; all others assessed cholesterol levels in late life.

\section{Obesity}

Only one of five studies found an increased risk of $A D$ in people with obesity (relative risk $1.4,95 \% \mathrm{Cl} 1.2-1.6){ }^{31}$ Five of seven studies found an increased risk of any dementia (relative risk 1.1, $95 \% \mathrm{Cl}$ 1.04-1.2). ${ }^{31}$ Generally, studies that measured weight at mid-life compared with late life showed a more consistent association and a higher risk of dementia.

In conclusion, the deleterious effects of vascular risk factors that are already present in mid-life seem relatively clear. These factors may play a causal role in AD by influencing neurodegenerative processes in the brain. Negative effects of vascular risk factors present in late life seem less evident. Findings also show that the risk of $A D$ and dementia increases with the number of vascular risk factors. ${ }^{32}$

\section{Nutrition}

Several nutritional factors have been investigated as potential risk factors for $A D$ and dementia in recent years. The question is which nutrients are essential for the healthy functioning of the brain.

\section{Vitamins}

Three of four studies (see reference 6 for an overview) found an increased risk of $A D$ in people with a high homocysteine level (e.g. relative risk $1.8,95 \% \mathrm{Cl} 1.3-2.5) .{ }^{33}$ Vitamin $\mathrm{B}_{6}$, vitamin $\mathrm{B}_{12}$ and folate have often been investigated simultaneously. Six studies were identified that tested the associations between these vitamins and risk of $A D .{ }^{6}$ In five of these studies, high folate intake in late life was found to reduce the risk of $A D$ (e.g. relative risk $0.4,95 \% \mathrm{Cl} 0.2-0.8$ ). ${ }^{34}$ Vitamin $B_{6}$ intake was associated with risk of $A D$ in only one of four studies, and $B_{12}$ intake in none of the studies. ${ }^{34}$ It has also been speculated that intake of antioxidative vitamins E, C, flovoid and betacarotene might influence risk of AD. Ten studies on these associations 
were identified. ${ }^{6}$ The most conclusive evidence was found for vitamin $E$, although only three of seven studies showed a reduced risk of $A D$ in people with a high vitamin $\mathrm{E}$ intake (e.g. relative risk $0.8,95 \% \mathrm{Cl}$ 0.7-1.0). ${ }^{35}$ Only one of six studies found evidence for an association with vitamin $\mathrm{C}$ intake, ${ }^{35}$ and no studies found associations with flovoids or beta-carotene.

\section{Fat Intake}

Fatty acid intake may affect the brain though inflammatory or artherosclerotic mechanisms; to date, five studies have investigated the association with dementia. ${ }^{6} \mathrm{~A}$ high intake of polyunsaturated fats in mid- to late life was associated with a reduced risk of $A D$ in three of four studies, whereas a high intake of saturated fats was associated with an increased risk of $A D$ in two of three studies (e.g. relative risk $2.2,95 \% \mathrm{Cl} 1.1-4.7){ }^{36}$

\section{Dietary Pattern}

Finally, a diverse diet including daily fruits and vegetables and two to three servings of fish per week ${ }^{37}$ and a Mediterranean-style diet rich in fish, fruits and vegetables are known to be associated with lower risk of $A D .^{38}$ Two of three studies investigating the association between weekly fish intake and risk of $A D$ found a reduced risk (e.g. relative risk $2.2,95 \% \mathrm{Cl} 1.1-4.7){ }^{39}$ In sum, some longitudinal studies suggest that higher intakes of folate, vitamin $B_{6}$, vitamin $E_{\text {, }}$ polyunsaturated fats, fruits and vegetables rich in antioxidants and fish are related to lower risk of $A D$, but results are inconsistent. ${ }^{40}$

\section{Conclusion}

Based on this brief overview of the empirical findings on potentially modifiable risk factors for $A D$, two main clusters of risk factors and prevention targets can be highlighted (see Table 1). First, an active and stimulating lifestyle including cognitive, social and physical activities reduces risk of $A D$, presumably by increasing brain reserve or reducing depression. Second, the absence of vascular risk factors reduces risk of $A D$, presumably by preventing neurodegenerative processes in the brain. However, there is currently not enough empirical evidence from longitudinal studies for serious conclusions to be drawn about other potential risk factors (motivational ability, emotional health and nutrition). ${ }^{40}$ Again, it is important to note that incident $A D$ or dementia cases were assessed on the basis of clinical features rather than neuropathological evidence.

To go one step further, results from randomised clinical trials (RCTS) on dementia prevention are not always as encouraging as results from the epidemiological studies cited. The existing RCTs - which are scarce in number - partially support the recommendations of physical exercise $^{41}$ as well as antihypertensive ${ }^{42}$ and cholesterol-lowering ${ }^{43}$ treatments to prevent the development of AD. There is little support from RCTs for preventative effects of cognitive training, ${ }^{44}$ diabetes treatment ${ }^{6}$ or nutritional strategies. ${ }^{40}$ We found no RCTs testing the influence of social activity and social network or treatment of depression on dementia risk. More prevention trials are warranted to investigate the preventative effects of an active and stimulating lifestyle on the one hand and vascular health on the other in delaying the onset of $A D$ or slowing its progression. Appropriate preventative measures would potentially reduce by millions the number of people with this devastating disease.

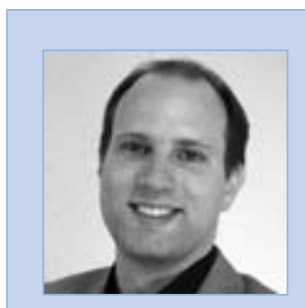

Simon Forstmeier is a Senior Researcher in the Department of Psychology, Division of Psychopathology and Clinical Intervention at the University of Zurich. His scientific focus is clinical geropsychology and psychotherapy with the elderly. He is directing a longitudinal study on modifiable risk factors for Alzheimer's dementia, which investigates in particular the role of motivational reserve.

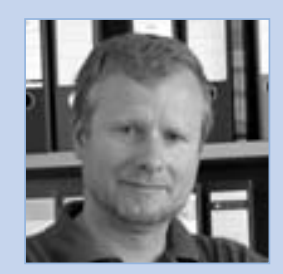

Andreas Maercker is a Professor of Psychopathology and Clinical Intervention at the University of Zurich. His scientific focus is issues in geropsychology research and post-traumatic stress disorder (PTSD). He directed a representative epidemiological study on stress-related disorders in the elderly and has written books and papers on psychotherapy with the elderly, PTSD therapy and online therapy. He is also working on social neuroscience related to stress-response syndromes.
1. Brookmeyer R, Johnsona E, Ziegler-Grahamb K, Arrighic HM, Alzheimers Dement, 2007;3:186-91.

2. Fries JF, Clin Geriatr Med, 2002;18:371-82.

3. Jedrziewski MK, Lee VM, Trojanowski JQ, Alzheimers Dement 2005; 1:152-60.

4. Hendrie HC, Albert MS, Butters MA, et al., Alzheimers Dement, 2006;2:12-32.

5. Whalley LJ, Dick FD, MCNeill G, Lancet Neurol, 2006;5: 87-96.

6. Coley N, Andrieu S, Gardette V, et al., Epidemiol Rev, 2008

7. Letenneur L, Gilleron V, Commenges D, et al., J Neurol Neurosurg Psychiatry, 1999;66:177-83.

8. Qiu C, Backman L, Winblad B, et al., Arch Neurol, 2001;58:2034-9.

9. Caamano-Isorna F, Corral M, Montes-Martinez A, Takkouche B, Neuroepidemiology, 2006;26:226-32.

10. Stern Y, Alzheimer Dis Assoc Disord, 2006;20:112-17.

11. Schmand B, Smit JH, Geerlings MI, Lindeboom J, Psychol Med, 1997:27:1337-44.

12. Elias MF, Beiser A, Wolf PA, et al., Arch Neurol, 2000;57:808-13.

13. Wilson RS, Bennett DA, Bienias JL, et al., Neurology, 2002;59:1910-14.

14. Stern Y, Gurland B, Tatemichi TK, et al., J Am Med Assoc, 1994;271:1004-10.

15. Kröger E, Andel R, Lindsay J, et al., Am J Epidemiol, 2008:167:820-30.

16. Forstmeier S, Maercker A, Psychol Aging, 2008;23:866-99.
17. Valenzuela MJ, Sachdev P, Psychol Med, 2006;36:441-54.

18. Luck T, Riedel-Heller SG, Kaduszkiewicz H, et al.; Dement Geriatr Cogn Disord, 2007;24:307-16.

19. Wilson RS, Schneider JA, Arnold SE, et al., Arch Gen Psychiatry, 2007;64:1204-12.

20. Ownby RL, Crocco E, Acevedo A, et al., Arch Gen Psychiatry, 2006;63:530-38.

21. Dal Forno G, Palermo MT, Donohue JE, et al., Ann Neurol, 2005;57:381-7

22. Wilson RS, Arnold SE, Schneider JA, et al., Neuroepidemiology, 2006;27:143-53.

23. Podewils L, Guallar E, Kuller LH, et al., Am J Epidemiol, 2005;161:639-51

24. Rovio S, Kareholt I, Helkala EL, et al., Lancet Neurol, 2005:4:705-11.

25. Wang HX, Karp A, Winblad B, Fratiglioni L, Am J Epidemiol, 2002;155:1081-7.

26. Saczynski JS, Pfeifer LA, Masaki KH, et al., Am J Epidemiol, 2006;163:433-40

27. Kloppenborg RP, van den Berg E, Kappelle L, Biessels GJ, Eur J Pharmacol, 2008;585:97-108.

28. Peila R, Rodriguez BL, Launer LJ, Diabetes, 2002;51:1256-62.

29. Launer $\sqcup$, Ross GW, Petrovitch H, et al., Neurobiol Aging, 2000;21:49-55.

30. Kivipelto M, Helkala EL, Laakso MP, et al., Ann Intern Med, 2002;137:149-55.

31. Gustafson D, Rothenberg E, Blennow K, et al., Arch Intern Med, 2003;163:1524-8.
32. Luchsinger JA, Reitz C, Honig LS, et al., Neurology, 2005;65:545-51.

33. Seshadri S, Beiser A, Selhub J, et al., N Eng/ J Med, 2002;346:476-83.

34. Corrada M, Kawas C, Hallfrisch J, et al., Alzheimers Dement, 2005;1:11-18

35. Engelhart MJ, Geerlings MI, Ruitenberg A, et al., J Am Med AsSOC, 2002;287:3223-9.

36. Morris MC, Evans DA, Bienias JL, et al., Arch Neurol, 2003;60:194-200.

37. Barberger-Gateau P, Raffaitin C, Letenneur L, et al., Neurology, 2007;69:1921-30

38. Scarmeas N, Stern Y, Tang MX, et al., Ann Neurol, 2006;59:912-21.

39. Morris MC, Evans DA, Bienias JL, et al., Arch Neurol, 2003;60:940-46.

40. Luchsinger JA, Noble JM, Scarmeas N, Curr Neurol Neurosci Rep, 2007;7:366-72.

41. Colcombe SJ, Kramer AF, Psychol Sci, 2003;14: 125-30.

42. Feigin $\mathrm{V}$, Ratnasabapathy $\mathrm{Y}$, Anderson $\mathrm{C}$, J Neurol Sci, 2005;229-230:151-5.

43. Jick H, Zornberg GL, Jick SS, et al., Lancet, 2000;356:1627-31

44. Gatz M, PLoS Med, 2005;2:e7.

45. Fratiglioni L, Wang HX, J Alzheimers Dis, 2007;12:11-22.

46. Fratiglioni L, Paillard-Borg S, Winblad B, Lancet Neurol, 2004;3:343-53. 